\title{
Zinc transporter-1 concentrates at the postsynaptic density of hippocampal synapses
}

\author{
Carlos Sindreu ${ }^{1,2^{*}}$, Àlex Bayés ${ }^{3,4}$, Xavier Altafaj $^{5}$ and Jeús Pérez-Clausell ${ }^{6}$
}

\begin{abstract}
Background: Zinc concentrates at excitatory synapses, both at the postsynaptic density and in a subset of glutamatergic boutons. Zinc can modulate synaptic plasticity, memory formation and nociception by regulating transmitter receptors and signal transduction pathways. Also, intracellular zinc accumulation is a hallmark of degenerating neurons in several neurological disorders. To date, no single zinc extrusion mechanism has been directly localized to synapses. Based on the presence of a canonical PDZ I motif in the Zinc Transporter-1 protein (ZnT1), we hypothesized that ZnT1 may be targeted to synaptic compartments for local control of cytosolic zinc. Using our previously developed protocol for the co-localization of reactive zinc and synaptic proteins, we further asked if ZnT1 expression correlates with presynaptic zinc content in individual synapses.

Findings: Here we demonstrate that $\mathrm{ZnT1}$ is a plasma membrane protein that is enriched in dendritic spines and in biochemically isolated synaptic membranes. Hippocampal CA1 synapses labelled by postembedding immunogold showed over a 5-fold increase in ZnT1 concentration at synaptic junctions compared with extrasynaptic membranes. Subsynaptic analysis revealed a peak ZnT1 density on the postsynaptic side of the synapse, $<10 \mathrm{~nm}$ away from the postsynaptic membrane. ZnT1 was found in the vast majority of excitatory synapses regardless of the presence of vesicular zinc in presynaptic boutons.
\end{abstract}

Conclusions: Our study has identified ZnT1 as a novel postsynaptic density protein, and it may help elucidate the role of zinc homeostasis in synaptic function and disease.

Keywords: ZnT1, Hippocampus, Postsynaptic density, Vesicular Zn ${ }^{2+}$, PDZ I motif, Dendritic spine

\section{Background}

Homeostasis of ionic or labile zinc $\left(\mathrm{Zn}^{2+}\right)$ in central neurons might be important in a range of physiological and pathological events. $\mathrm{Zn}^{2+}$ may act as a co-transmitter at certain glutamatergic synapses, participate in neuronal signal transduction, modulate memory formation and nociception, or promote neurodegeneration upon brain insults $[1,2]$. Marked differences in the levels of intracellular $\mathrm{Zn}^{2+}$ are found among cellular compartments owing to the coordinated actions of two families of zinc transporter proteins, Slc30a (ZnT1-10) and Slc39 (ZIP1-14). Whereas $\mathrm{ZnTs}$ export $\mathrm{Zn}^{2+}$ away from the cytosol into organelles or the extracellular space, ZIPs shuttle $\mathrm{Zn}^{2+}$ in opposite direction [3]. Cytosolic $\mathrm{Zn}^{2+}$ is estimated to be in the

\footnotetext{
* Correspondence: csindreu@ub.edu

'Department of Pharmacology, University of Barcelona, Barcelona 08036, Spain

2Department of Pharmacology, University of Washington, Seattle 98195, USA Full list of author information is available at the end of the article
}

subnanomolar range, but $\mathrm{Zn}^{2+}$ transients in neurons have been reported following strong depolarization or oxidation [4]. Accumulation of cytosolic $\mathrm{Zn}^{2+}$ is common in degenerating neurons in models of epilepsy, ischemia or Parkinson's disease [5-7]. In contrast, high concentrations of zinc are normally found at synapses [8]. Bound zinc maintains the organization of the postsynaptic density (PSD) [9], where it associates with Shank2/3 protein scaffolds [10] and SAP-102 [11]. In addition, a subset of excitatory boutons up-take $\mathrm{Zn}^{2+}$ into glutamatergic vesicles via $\mathrm{ZnT} 3$ [12]. One may expect, therefore, that specific plasma membrane proteins support $\mathrm{Zn}^{2+}$ homeostasis at synapses, but their identity remains elusive. One candidate protein is ZnT1 [13]. ZnT1 localizes to the plasma membrane, reduces cytosolic $\mathrm{Zn}^{2+}$, confers resistance against $\mathrm{Zn}^{2+}$ toxicity, and it is expressed in several brain regions $[13,14]$. We previously developed a protocol that allows for the co-localization of neuronal proteins and vesicular $\mathrm{Zn}^{2+}$ by combining immunogold electron microscopy 
with zinc histochemistry [15]. Here we used a similar approach to ask whether ZnT1 localizes to synapses. We focused on the CA1 region of the hippocampus because only half of CA3-to-CA1 synapses contain vesicular $\mathrm{Zn}^{2+}$ [15], allowing for direct comparisons between the presence of vesicular $\mathrm{Zn}^{2+}$ and $\mathrm{ZnT} 1$ expression.

\section{Results and discussion}

\section{$\mathrm{ZnT1}$ is found in synaptic regions in hippocampus}

Immunostaining for $\mathrm{ZnT} 1$ in the $\mathrm{CA} 1$ region of the hippocampus was particularly conspicuous in somata and apical dendrites of pyramidal cells (Figure 1A), prompting us to analyze its synaptic distribution. In mature hippocampal cultures (DIV 21), ZnT1 co-localized with GluR1(+) and SynGAP(+) puncta along dendritic shafts (Figure 1B), indicating the presence of $\mathrm{ZnT} 1$ in spines. As predicted, ZnT1 appeared as a $55 \mathrm{kDa}$ band in the cytoplasmic fraction of hippocampal lysates (Figure 1C). When synaptic and extrasynaptic membranes were separated, ZnT1 was enriched in the synaptic (i.e. Tritoninsoluble and PSD95-rich) plasma membrane fraction (Figure 1C). The presence of ZnT1 at synapses was independently confirmed by mass spectrometry-based analysis of adult mouse brain synaptosomal fractions (Bayés $\mathrm{A}$, personal communication).

\section{$\mathrm{ZnT1}$ concentrates at the postsynaptic density}

We first established the ultrastructural distribution of ZnT1 in Lowicryl-embedded CA1 stratum radiatum in the absence of zinc histochemistry. Postembedding immunogold showed that $80 \pm 1 \%$ of ZnT1 particles localized to the plasma membrane, including synaptic junctions, dendrites, and astrocytes ( $\mathrm{n}=1,372$ gold particles; area analyzed $=354 \mu \mathrm{m}^{2}$; Figures $2 \mathrm{~A}-\mathrm{D}$ ). ZnT1 particles often accumulated at membrane densities of apposed plasma membranes, including synaptic junctions or presumed puncta adherentia. Indeed, quantitative analysis revealed that the ZnT1 surface density was $>5$-fold higher in synaptic membranes compared with extrasynaptic membranes in spines, dendritic shafts, or glia $(n=334$ particles over 88.4 $\mu \mathrm{m}$ of membrane; Figure 2E; $\mathrm{P}<0.001$ for all comparisons). In the absence of primary antibody, the density of synaptic particles was markedly lower $(0.04 \pm$ 0.03 particles $/ \mu \mathrm{m})$. The small fraction of intracellular ZnT1 labeling was mainly associated with postsynaptic membranous material (67 $\pm 2 \%$ of intracellular particles) (Figure 2A).

Synaptic ZnT1 labeling was widespread, encompassing $76 \pm 3 \%$ of asymmetric synapses in single ultrathin sections (3.2 \pm 1.7 particles/synapse; range $1-9 ; \mathrm{n}=175$ synapses). Particle distribution along the axis perpendicular to the synaptic junction revealed a main peak on the cytoplasmic side of the postsynaptic membrane $(7.1 \pm 0.8 \mathrm{~nm}$ from the membrane; $\mathrm{n}=339$ particles and 132 synapses) (Figure $2 \mathrm{~F}$ ). Further, tangential analysis of synaptic $\mathrm{ZnT} 1$ revealed a moderate lateral increase along the PSD length $(n=111$ particles and 46 synapses; Figure 2G). The results indicate that ZnT1 concentrates in the postsynaptic membrane of hippocampal synapses, in keeping with the biochemical data.

\section{Synaptic ZnT1 expression and vesicular $\mathrm{Zn}^{2+}$}

To determine if synaptic $\mathrm{ZnT} 1$ expression correlates with the presence $(\mathrm{ZN}+)$ or absence $(\mathrm{ZN}-)$ of vesicular $\mathrm{Zn}^{2+}$ in presynaptic boutons, we performed zinc histochemistry before tissue embedding. Previous studies have shown that $\mathrm{ZN}+$ synapses selectively co-express the obligatory vesicular transporter $\mathrm{ZnT} 3$, and make up $~ 45 \%$ of axospinous synapses in CA1 [15]. Indeed, silver granules reporting vesicular $\mathrm{Zn}^{2+}$ were invariably found in a fraction of boutons and readily distinguished from immunogold particles (Figure 3A). As earlier, ZnT1 particles were significantly

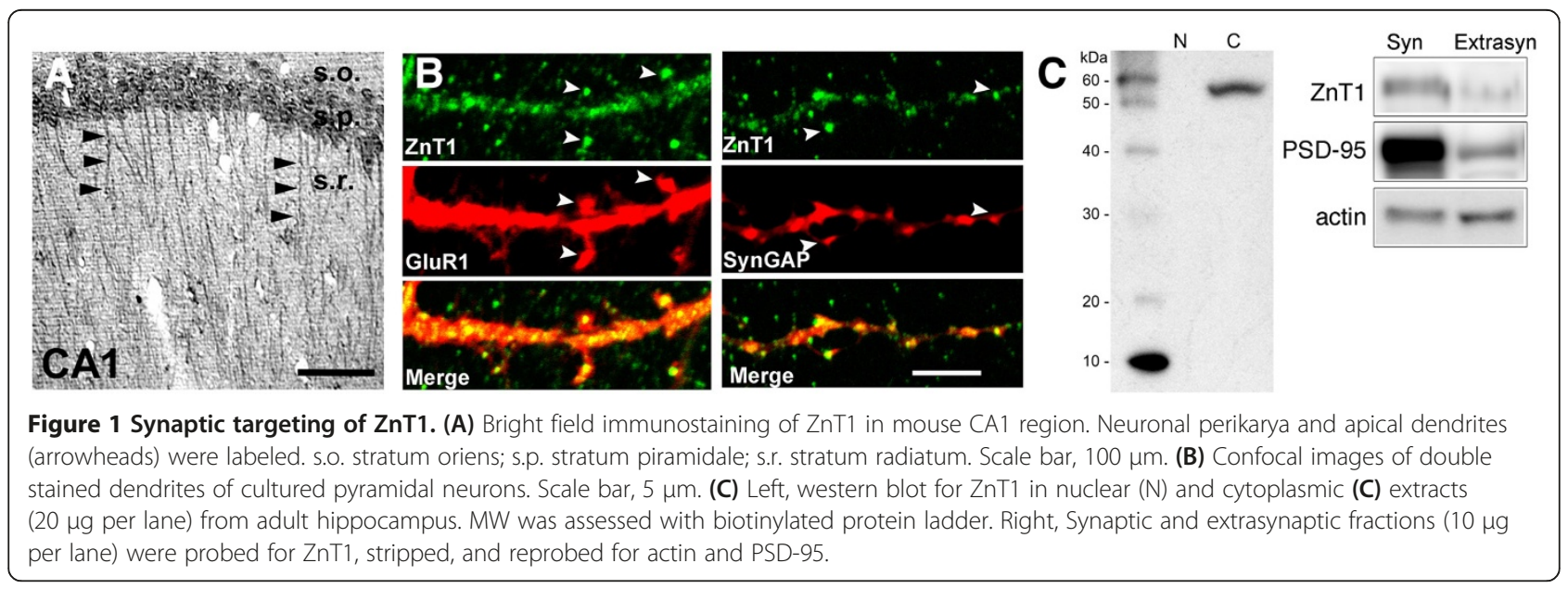




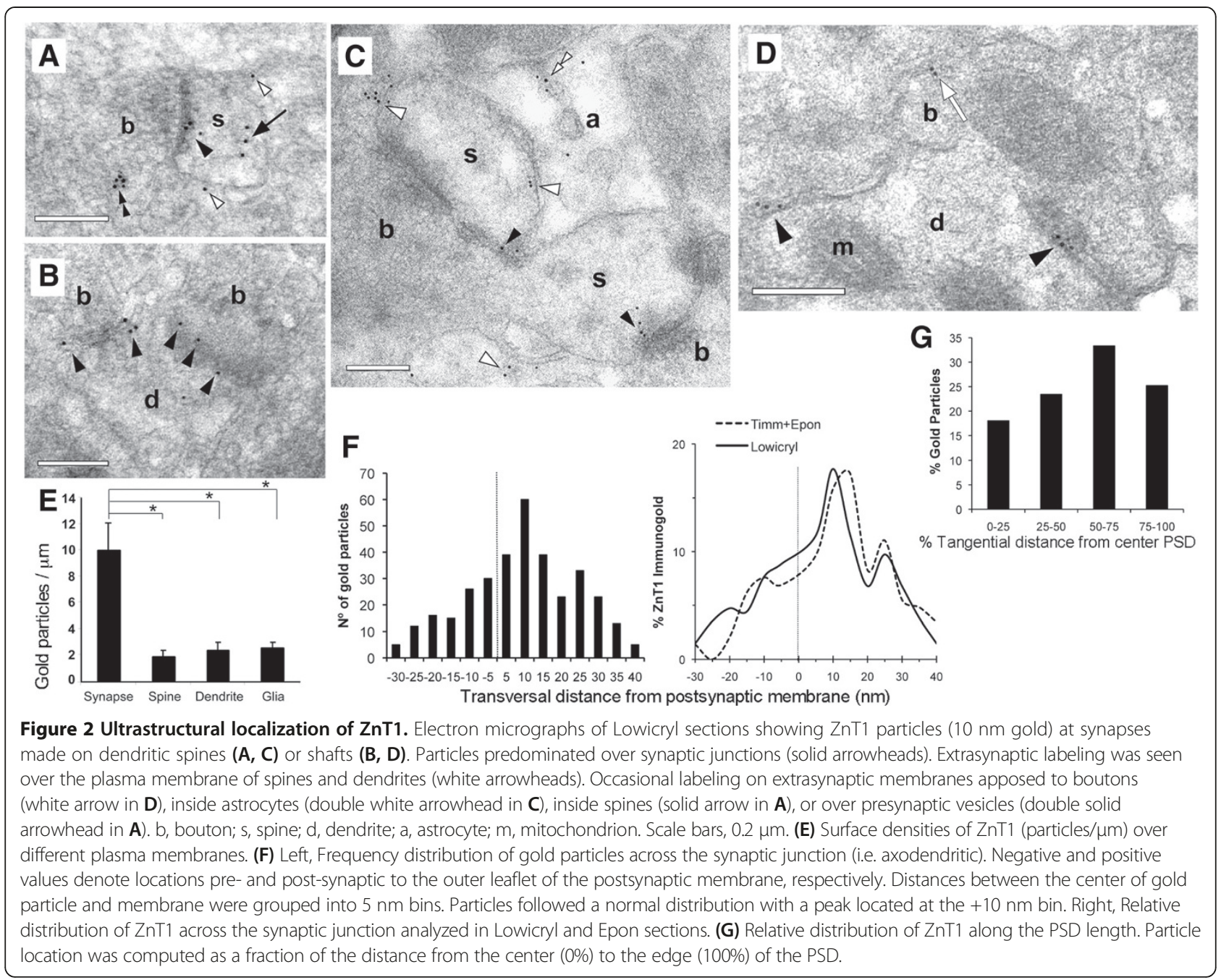

enriched in synaptic junctions (area analyzed $=316 \mu \mathrm{m}^{2}$; membrane length $=285.4 \mu \mathrm{m} ; \mathrm{n}=522$ particles; Figure $3 \mathrm{C}$ ), and accumulated just inside the postsynaptic membrane $(9.2 \pm 1.2 \mathrm{~nm} ; 145$ particles; Figure 2F). Synaptic ZnT1 labeling was found with similar frequencies at $\mathrm{ZN}+$ and $\mathrm{ZN}$ - axospinous synapses in single sections $(58 \pm 1 \%$ of $\mathrm{ZN}+$ synapses, and $60 \pm 3 \%$ of $\mathrm{ZN}$ - synapses; $\mathrm{n}=143$ synapses; $\mathrm{P}=0.9$; Figure $3 \mathrm{~A}, \mathrm{~B}$ ). Likewise, the number of synaptic ZnT1 particles was similar between both populations $(2.2 \pm 0.2$ particles/PSD at $\mathrm{ZN}+$, and $1.5 \pm 0.8$ particles/PSD at $\mathrm{ZN}-; \mathrm{n}=214$ particles; $\mathrm{P}=0.2$ ). Serial section analysis confirmed the absence of vesicular $\mathrm{Zn}^{2+}$ in synapses labeled for $\mathrm{ZnT} 1$ that had been identified as $\mathrm{ZN}$ - in single sections $(n=51$; Figure $3 B$, right). Moreover, although distal segments of stratum radiatum are known to stain for $\mathrm{Zn}^{2+}$ more heavily [12], we found similar ZnT1 densities at proximal $(<20 \mu \mathrm{m}$ from soma $)$ and distal (> $100 \mu \mathrm{m}$ away) synapses $(\mathrm{n}=103$ and 199 synapses, respectively; $\mathrm{P}=0.2$ ). We conclude that postsynaptic $\mathrm{ZnT} 1$ expression does not correlate with vesicular $\mathrm{Zn}^{2+}$ content in individual synapses.

The present results provide compelling evidence that $\mathrm{ZnT} 1$ is preferentially expressed in synaptic membrane domains in rodent hippocampus (mouse and rat), and identify ZnT1 as a novel PSD protein. ZnT1 was found in the somatodendritic compartment in region CA1, it co-localized with PSD proteins GluR1 and SynGAP in dendritic spine-like structures, and it was enriched in synaptic membrane fractions compared with extrasynaptic membrane. High-resolution immunogold electron microscopy confirmed and extended these results, showing that ZnT1 densities were over 5-fold higher in postsynaptic junction membranes than in other membrane domains, including extrasynaptic spine membrane, shafts, boutons, somata or astrocytes. Furthermore, the ZnT1 particle distribution across the synapse, peaking within $10 \mathrm{~nm}$ 


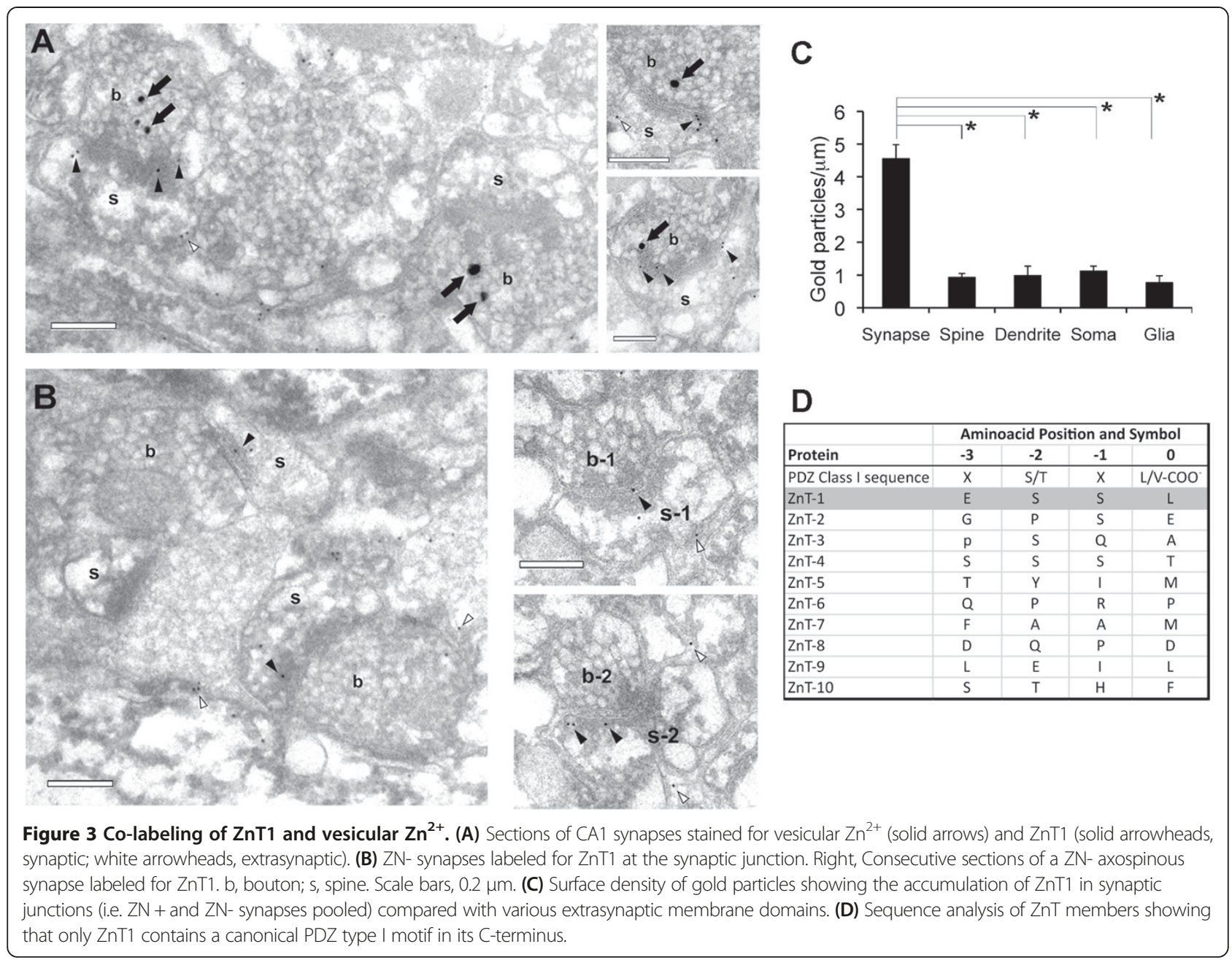

inside the postsynaptic membrane, suggests that $\mathrm{ZnT} 1$ is an integral transmembrane protein at the PSD, which is consistent with the predicted 6 hydrophobic regions in its aminoacid sequence [13]. The fact that ZnT1 surface density was similarly low among several extrasynaptic regions suggests that, in addition to the secretory pathway targeting ZnT1 to the cell surface, a synapse-specific mechanism may retain $\mathrm{ZnT} 1$ at the PSD. One possibility is that ZnT1 interacts via its cytoplasmic regions with other PSD proteins to concentrate at synapses. Interestingly, $\mathrm{ZnT} 1$ is the only member of its family that presents a consensus PDZ Class I motif at its C-terminus (Figure 3D), the latter showing $100 \%$ identity in humans. Several scaffolding molecules recognize PDZ motifs, including PSD-95, MPP1 or Lin7. Since the ZnT1 PDZ motif (ESSL) is very similar to that of GluN2A/B (ESDV), one may speculate that proteins of the PSD-95 family may also be retaining ZnT1 at the PSD.

Notably, ZnT1 was not restricted to the subset of synapses containing vesicular $\mathrm{Zn}^{2+}$. This widespread distribution implies a general physiological role for $\mathrm{ZnT} 1$ at synapses independently of the actions of $\mathrm{ZnT3}$ or vesicular $\mathrm{Zn}^{2+}$. Accordingly, organizing synaptic scaffolds appear particularly sensitive to intracellular $\mathrm{Zn}^{2+}$, leading to changes in PSD morphology upon zinc chelation [16]. It is therefore possible that zinc status itself affects ZnT1 localization or expression. ZnT1 may be responsible for counteracting basal ZIP-mediated influx of interstitial $\mathrm{Zn}^{2+}$ [17] or for removing $\mathrm{Zn}^{2+}$ liberated in dendrites from redox-sensitive metalloproteins, such as metallothionein-3 or PKC $[18,19]$. In keeping with this, deletion of metallothionein-3 prevents the build-up of cytosolic $\mathrm{Zn}^{2+}$ following seizures [20]. Additional roles for $\mathrm{ZnT} 1$ besides $\mathrm{Zn}^{2+}$ transport, such as modulation of MAPK or $\mathrm{Ca}^{2+}$ signaling [21,22], or targeting of potential PSD protein partners, cannot be ruled out. Genetic deletion of ZnT1 is embryonic lethal [23]. Given the high concentration of elemental zinc and ZnT1 at PSDs, it will be interesting to learn how conditional deletion of ZnT1 affects synaptic structure and function. 


\section{Conclusion}

$\mathrm{ZnT} 1$ is the first zinc transporter protein shown to concentrate at the PSD. The presence of ZnT1 in the vast majority of excitatory synapses in hippocampus suggests an unanticipated basic role for ZnT1 in synaptic function that warrants further investigation.

\section{Materials and methods Antibodies}

Rabbit anti-ZnT1 antibodies were obtained from William F. Silverman (Ben-Gurion University). The specificity of the antibody, raised against the carboxyl-tail of mouse ZnT1 [14], was previously demonstrated by transfection of HEK-293 cells with mouse ZnT1 plasmid, and by siRNAmediated knockdown in rat cortical neurons [24]. Rabbit anti-GluR1 antibody, mouse anti-PSD95, and mouse antiactin were from Millipore; rabbit anti-SynGAP was from Affinity Bioreagents.

\section{Immunohistochemistry}

All procedures followed present regulations for animal care and handling and were approved by the University of Barcelona Ethical Committee. BALB/c mice (2 month-old) were anesthesized and perfused with heparinized saline, and $4 \%$ formaldehyde $/ 0.1 \%$ glutaraldehyde in $0.1 \mathrm{M}$ phosphate buffer (PB; pH 7.4). Brains were postfixed for $2 \mathrm{hr}$, cryoprotected in $30 \%$ sucrose in $\mathrm{PB}$, frozen, and cut into $40 \mu \mathrm{m}$-thick sections. Brain slices were freeze-thawed twice with liquid $\mathrm{N}_{2}$, rinsed in $\mathrm{PB}$, incubated in $0.5 \%$ $\mathrm{NaBH}_{4}$ in $\mathrm{PB}$ for 15 min, and blocked in 10\% NGS, $1 \%$ BSA and $0.2 \mathrm{M}$ glycine in PBS for $2 \mathrm{hr}$. Slices were incubated in rabbit anti-ZnT1 antibody $(1: 500)$ at $4^{\circ} \mathrm{C}$ for $2 \mathrm{~d}$, then rinsed and incubated in biotinylated goat anti-rabbit IgG (1:200) at $4^{\circ} \mathrm{C}$ for $8 \mathrm{hr}$, rinsed again, and incubated in streptavidin-biotinylated HRP (1:300). The HRP was developed in $0.05 \% \mathrm{DAB}$ and $0.001 \% \mathrm{H} 2 \mathrm{O} 2$ in Tris- $\mathrm{HCl}$ buffer.

\section{Neuronal cultures}

Hippocampi were collected from postnatal day 1 pups, digested with $10 \mathrm{U} / \mathrm{ml}$ papain in Hank's buffer, dissociated, and plated in Neurobasal A with supplements on poly-D-lysine-coated coverslips. Cultures were fixed with $4 \%$ formaldehyde, $4 \%$ sucrose in PB, and then $100 \%$ methanol for $10 \mathrm{~min}$ at $4^{\circ} \mathrm{C}$. Tyramide-Cyanine 3 signal amplification was used according to manufacturer instructions (Perkin Elmer) to detect binding of anti-GluR1 $(1: 6,000)$ or anti-SynGAP $(1: 8,000)$ antibodies. Immunolabeling with anti-ZnT1 antibodies (1:500) was detected with goat anti-rabbit Alexa488 IgG. Images were captured using an Olympus Fluoview FV600 confocal microscope and $x 63$ objectives. Z-series of 4 consecutive optical sections $(0.6 \mu \mathrm{m})$ were acquired using sequential scanning and Kalman filter.

\section{Immunoblotting}

Hippocampi were homogenized in 10 volumes of buffer containing $10 \mathrm{mM}$ HEPES, $\mathrm{pH} 7.5,0.32 \mathrm{M}$ sucrose, $2 \mathrm{mM}$ EDTA, $2 \mathrm{mM}$ EGTA, $5 \mathrm{mM}$ DTT, and protease inhibitor cocktail tablet (Roche), followed by centrifugation at $800 \mathrm{~g}$ for $10 \mathrm{~min}$. Supernatants were saved as the cytoplamic fraction. Pellets were resuspended in homogenization buffer plus $0.5 \%$ Nonidet P-40, and centrifuged again to obtain crude nuclear fractions. These nuclear fractions were resuspended in extraction buffer containing $10 \mathrm{mM}$ HEPES, pH 7.5, $400 \mathrm{mM} \mathrm{NaCl}, 10 \%$ glycerol, 0.5\% Nonidet P-40, 2 mM EDTA, 2 mM EGTA, $5 \mathrm{mM}$ DTT, and protease inhibitor cocktail. Suspensions were rocked for $30 \mathrm{~min}$ on ice and centrifuged at $16,700 \mathrm{~g}$ for $10 \mathrm{~min}$. Resulting supernatants were used as nuclear extracts. The cytoplasmic fraction was centrifuged $(10,200 \mathrm{~g}, 15 \mathrm{~min})$ to obtain the crude synaptosomal pellet, resuspended with $0.5 \%$ Triton, rocked, and centrifuged at 21,000 g for $40 \mathrm{~min}$. The PSD-enriched pellet was resuspended in LB. The supernatant containing non-PSD membranes was precipitated with $-20^{\circ} \mathrm{C}$ acetone. Equal protein amounts were separated by SDS-PAGE in $8 \%$ gels. PVDF membranes were blocked with 5\% BSA, $0.1 \%$ Tween-20 in Tris-buffered saline (TBS), and incubated overnight at $4^{\circ} \mathrm{C}$ with $\mathrm{ZnT} 1$ antibodies $(1: 1,000)$, or $1 \mathrm{~h}$ at RT with PSD-95 $(1: 10,000)$ or actin $(1: 5,000)$ antibodies. Proteins were detected with HRP-conjugated secondary antibodies and visualized by chemiluminescence.

\section{Post-embedding immunoelectron microscopy}

For acrylic embedding, brains from two Wistar rats (250$300 \mathrm{~g}$ ) were perfused with $4 \%$ formaldehyde, $0.2 \%$ glutaraldehyde and $0.2 \%$ picric acid in $\mathrm{PB}, \mathrm{pH}$ 7.4. Vibratome slices were cryoprotected in glycerol, frozen in liquid propane, freeze-substituted in $0.5 \%$ uranyl acetate in methanol at $-90^{\circ} \mathrm{C}$, infiltrated with Lowicryl HM20 at $-45^{\circ} \mathrm{C}$, and polymerized with UV light. For $\mathrm{Zn}^{2+}$ staining and epoxy embedding, we used our previous protocol (Sindreu'03). Briefly, two rats were perfused with $0.1 \% \mathrm{Na}_{2} \mathrm{~S}$ and $2.5 \%$ glutaraldehyde in $\mathrm{PB}$, followed by $1 \%$ formaldehyde, $2.5 \%$ glutaraldehyde and $0.2 \%$ picric acid. Slices were stained with the Neo-Timm's method (Danscher, 1981), post-fixed using an osmium-free protocol (Phend et al., 1995) and flat-embedded in epoxy resin (Embed-812; EMS). Lowicryl or epoxy sections $(60-70 \mathrm{~nm})$ were collected on gold grids (200 mesh), incubated in $0.5 \% \mathrm{NaBH}_{4}$ in $50 \mathrm{mM}$ Trisbuffered saline (TBS; $\mathrm{pH}=7.6$ ) for $10 \mathrm{~min}$, rinsed in $0.005 \%$ Tergitol NP-10 in TBS (TBST), blocked in $10 \%$ NGS, $2 \% \mathrm{BSA}$ and $50 \mathrm{mM}$ glycine in TBST, and reacted with anti-ZnT1 antibodies (1:200) overnight. Grids were rinsed in TBST and TBST/pH 8.2, and incubated in $10 \mathrm{~nm}$ gold-conjugated goat anti-rabbit $\mathrm{F}(\mathrm{ab})_{2}$ fragments (1:30; British BioCell) for $2 \mathrm{~h}$. Grids were rinsed and counterstained. 
Electron micrographs were taken at $\times 30,000$ magnification, recorded by a CCD camera (Gatan Inc.) and analysed with Canvas software (Deneba Systems, Inc.). The CA1 stratum radiatum was examined by random systematic sampling of visual fields $(1 / 3)$ at $10-200 \mu \mathrm{m}$ from the pyramidal cell layer. Synapses were defined as those structures showing synaptic vesicles in the presynaptic element and a postsynaptic membrane specialization. Labeling at the synaptic junction was analysed in transversely cut synaptic profiles. To assess the transversal location of synaptic gold particles, we measured the distance from the outer margin of the postsynaptic junctional membrane to the center of each gold particle in a line perpendicular to the membrane. Particles were considered 'synaptic' when found within a radius of $30 \mathrm{~nm}$ from the postsynaptic junctional membrane, and 'extrasynaptic' when located further away. Similarly, a $30 \mathrm{~nm}$ limit was used to differentiate between surface and intracellular labeling. To assess the tangential location of particles, the distance of each gold particle from the centre of the PSD was normalized to the half-length of the PSD profile. PSD lengths shorter than $200 \mathrm{~nm}$ were excluded for tangential analysis. To calculate the surface density, gold particles in each membrane compartment were counted in digital EM pictures, and effective membrane lengths measured. Double staining for vesicular $\mathrm{Zn}^{2+}$ and $\mathrm{ZnT1}$ was studied in synapses located within $4 \mu \mathrm{m}$ from the net surface of the vibratome slice to avoid false negative counts [15]. T-test and ANOVA were used for pair-wise and multiple comparisons, respectively. Significance was set at 0.05. Data are given as mean \pm standard error of mean unless otherwise noted.

\section{Competing interests}

The authors declare they have no competing interests.

\section{Authors' contributions}

CS performed experiments. CS, AB, XA and JPC analyzed the data. CS wrote the manuscript with input from all authors. All authors read and approved the final manuscript.

\section{Acknowledgements}

We thank Zeev Silverman for the gift of ZnT1 antibodies. This work was supported by the Fundacio Marato de TV3. CS and AB are supported by the Ramon y Cajal Research Career Program. XA is supported by the Miguel Servet Research Career Program.

\footnotetext{
Author details

'Department of Pharmacology, University of Barcelona, Barcelona 08036, Spain. ${ }^{2}$ Department of Pharmacology, University of Washington, Seattle 98195, USA. ${ }^{3}$ Molecular Physiology of the Synapse Laboratory, Biomedical Research Institute Sant Pau, 08025 Barcelona, Spain. ${ }^{4}$ Universitat Autònoma de Barcelona, 08193 Bellaterra, Spain. ${ }^{5}$ Biomedical Research Institute Bellvitge, L'Hospitalet de Llobregat 08908, Spain. ${ }^{6}$ Department of Cell Biology, University of Barcelona, Barcelona 08028, Spain.
}

Received: 29 January 2014 Accepted: 28 February 2014 Published: 7 March 2014

\section{References}

1. Sindreu C, Storm DR: Modulation of neuronal signal transduction and memory formation by synaptic zinc. Front Behav Neurosci 2011, 5:68.

2. Sensi SL, Paoletti P, Koh JY, Aizenman E, Bush Al, Hershfinkel M: The neurophysiology and pathology of brain zinc. J Neurosci 2011, 31:16076-16085.

3. Huang L, Tepaamorndech S: The SLC30 family of zinc transporters - a review of current understanding of their biological and pathophysiological roles. Mol Aspects Med 2013, 34:548-560

4. Carter RE, Aiba I, Dietz RM, Sheline CT, Shuttleworth CW: Spreading depression and related events are significant sources of neuronal Zn2+ release and accumulation. J Cereb Blood Flow Metab 2011, 31:1073-1084.

5. Lee JY, Cole TB, Palmiter RD, Koh JY: Accumulation of zinc in degenerating hippocampal neurons of ZnT3-null mice after seizures: evidence against synaptic vesicle origin. J Neurosci 2000, 20:RC79.

6. Koh JY, Suh SW, Gwag BJ, He YY, Hsu CY, Choi DW: The role of zinc in selective neuronal death after transient global cerebral ischemia. Science 1996, 272:1013-1016.

7. Lee JY, Son HJ, Choi JH, Cho E, Kim J, Chung SJ, Hwang O, Koh JY: Cytosolic labile zinc accumulation in degenerating dopaminergic neurons of mouse brain after MPTP treatment. Brain Res 2009, 1286:208-214

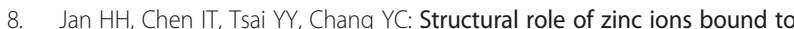
postsynaptic densities. J Neurochem 2002, 83:525-534.

9. Baron MK, Boeckers TM, Vaida B, Faham S, Gingery M, Sawaya MR, Salyer D, Gundelfinger ED, Bowie JU: An architectural framework that may lie at the core of the postsynaptic density. Science 2006, 311:531-535.

10. Grabrucker AM, Knight MJ, Proepper C, Bockmann J, Joubert M, Rowan M, Nienhaus GU, Garner CC, Bowie JU, Kreutz MR, Gundelfinger ED, Boeckers TM: Concerted action of zinc and ProSAP/Shank in synaptogenesis and synapse maturation. EMBO J 2011, 30:569-581.

11. El-Husseini AE, Topinka JR, Lehrer-Graiwer JE, Firestein BL, Craven SE, Aoki C, Bredt DS: Ion channel clustering by membrane-associated guanylate kinases. Differential regulation by N-terminal lipid and metal binding motifs. J Biol Chem 2000, 275:23904-23910.

12. Cole TB, Wenzel HJ, Kafer KE, Schwartzkroin PA, Palmiter RD: Elimination of zinc from synaptic vesicles in the intact mouse brain by disruption of the ZnT3 gene. Proc Natl Acad Sci USA 1999, 96:1716-1721.

13. Palmiter RD, Findley SD: Cloning and functional characterization of a mammalian zinc transporter that confers resistance to zinc. EMBO J 1995, 14:639-649.

14. Sekler I, Moran A, Hershfinkel M, Dori A, Margulis A, Birenzweig N, Nitzan Y Silverman WF: Distribution of the zinc transporter ZnT-1 in comparison with chelatable zinc in the mouse brain. J Comp Neurol 2002, 447:201-209.

15. Sindreu CB, Varoqui H, Erickson JD, Pérez-Clausell J: Boutons containing vesicular zinc define a subpopulation of synapses with low AMPAR content in rat hippocampus. Cereb Cortex 2003, 13:823-829.

16. Grabrucker S, Jannetti L, Eckert M, Gaub S, Chhabra R, Pfaender S, Mangus K, Reddy PP, Rankovic V, Schmeisser MJ, Kreutz MR, Ehret G, Boeckers TM, Grabrucker AM: Zinc deficiency dysregulates the synaptic ProSAP/Shank scaffold and might contribute to autism spectrum disorders. Brain 2014 137:137-152.

17. Qian J, Xu K, Yoo J, Chen TT, Andrews G, Noebels JL: Knockout of Zn transporters Zip-1 and Zip-3 attenuates seizure-induced CA1 neurodegeneration. J Neurosci 2011, 31:97-104.

18. Aizenman E, Stout AK, Hartnett KA, Dineley KE, McLaughlin B, Reynolds IJ: Induction of neuronal apoptosis by thiol oxidation: putative role of intracellular zinc release. J Neurochem 2000, 75:1878-1888.

19. Knapp LT, Klann E: Superoxide-induced stimulation of protein kinase $C$ via thiol modification and modulation of zinc content. J Biol Chem 2000, 275:24136-24145.

20. Lee JY, Kim JH, Palmiter RD, Koh JY: Zinc released from metallothionein-iii may contribute to hippocampal CA1 and thalamic neuronal death following acute brain injury. Exp Neurol 2003, 184:337-347.

21. Jirakulaporn T, Muslin AJ: Cation diffusion facilitator proteins modulate Raf-1 activity. J Biol Chem 2004, 279:27807-27815.

22. Levy S, Beharier O, Etzion Y, Mor M, Buzaglo L, Shaltiel L, Gheber LA, Kahn J, Muslin AJ, Katz A, Gitler D, Moran A: Molecular basis for zinc transporter 1 action as an endogenous inhibitor of L-type calcium channels. J Biol Chem 2009, 284:32434-32443. 
23. Andrews GK, Wang H, Dey SK, Palmiter RD: Mouse zinc transporter 1 gene provides an essential function during early embryonic development. Genesis 2004, 40:74-81.

24. Ohana E, Sekler I, Kaisman T, Kahn N, Cove J, Silverman WF, Amsterdam A, Hershfinkel M: Silencing of ZnT-1 expression enhances heavy metal influx and toxicity. J Mol Med 2006, 84:753-763.

doi:10.1186/1756-6606-7-16

Cite this article as: Sindreu et al: Zinc transporter-1 concentrates at the postsynaptic density of hippocampal synapses. Molecular Brain 2014 7:16.

\section{Submit your next manuscript to BioMed Central} and take full advantage of:

- Convenient online submission

- Thorough peer review

- No space constraints or color figure charges

- Immediate publication on acceptance

- Inclusion in PubMed, CAS, Scopus and Google Scholar

- Research which is freely available for redistribution 